\title{
Which Social Media Facilitate Online Public Opinion in China?
}

\section{Daniela Stockmann \& Ting Luo}

To cite this article: Daniela Stockmann \& Ting Luo (2017) Which Social Media Facilitate Online Public Opinion in China?, Problems of Post-Communism, 64:3-4, 189-202, DOI: 10.1080/10758216.2017.1289818

To link to this article: https://doi.org/10.1080/10758216.2017.1289818

\section{(2) Published with license by Taylor \& Francis@ Daniela Stockmann and Ting Luo.}

\section{Published online: 30 Mar 2017.}

Submit your article to this journal $\sqsubset$

\section{џll Article views: 943}

Q View related articles $\longleftarrow$

View Crossmark data ־ 


\title{
Which Social Media Facilitate Online Public Opinion in China?
}

\author{
Daniela Stockmann ${ }^{1}$ and Ting Luo ${ }^{2}$ \\ ${ }^{1}$ Hertie School of Governance, Berlin, Germany \\ ${ }^{2}$ Department of Political Science, Leiden University, Leiden, The Netherlands
}

\begin{abstract}
Why does online public opinion emerge in some social media more easily than in others? Building on research on authoritarian deliberation, we describe spaces for political discussion in Chinese cyberspace in terms of interactivity, which results in different forms of political discussion. Drawing on semi-structured qualitative expert interviews with information and communications technology professionals at Tencent, Weibo, and Baidu, we explain how major social media differ in terms of their structure and the company's motivation. We specify which features are more likely to facilitate the emergence of online public opinion in Chinese social media and provide preliminary evidence from 92 semi-structured interviews with Internet users.
\end{abstract}

\section{INTRODUCTION}

In August 2015, at the harbor in Tianjin, 800 tons of chemicals exploded. Residents of Tianjin took pictures and videos with their mobile phones and posted them on the Internet. Once posted online, the images were picked up by market-based media that brought the information to the center of public discourse. In most liberal democracies, online discourse about such an event would be taken for granted, but this was not the case in China, where political views could be voiced in private but not publicized in media - until the digital age. New media have facilitated the rise of online public opinion, whereby stories discussed on the Web may suddenly be funneled into the public discourse.

Address correspondence to Daniela Stockmann, Professor of Digital Politics and Media, Hertie School of Governance, Friedrichstrasse 180, 10117 Berlin, Germany. Email: ds@daniestockmann.net, or to Ting Luo, Department of Political Science, Faculty of Social Sciences, Leiden University, 2333 AK Leiden, The Netherlands. Email: t.luo@fsw.leidenuniv.nl.

(C) Daniela Stockmann and Ting Luo.

This is an Open Access article distributed under the terms of the Creative Commons Attribution-NonCommercial-NoDerivatives License (http://creativecommons.org/licenses/by-nc-nd/4.0/), which permits noncommercial re-use, distribution, and reproduction in any medium, provided the original work is properly cited, and is not altered, transformed, or built upon in any way.

Color versions of one or more of the figures in the article can be found online at www.tandfonline.com/mppc.
Social media can exert great pressure on the regime to become responsive. For example, after the Tianjin explosion, President Xi Jinping called for urgent nationwide checks on dangerous chemicals and reviews of workplace safety, and Premier Li Keqiang visited the scene to investigate the situation. The former vice mayor of Tianjin, Yang Dongliang, at the time a member of the Central Committee of the Chinese Communist Party and director of the State Administration for Work Safety, was sacked for suspected "serious breaches of discipline and the law." Another eleven government and port officials were prosecuted for their negligence over the massive explosions. Reilly (2012) has demonstrated that such public pressures limit the policy options that the central leadership takes under consideration, affect negotiating strategy, shape official rhetoric and public debate over policy, and affect the timing and direction of specific policy choices (Meng, Pan, and Yang, 2014)

To a certain extent, online discussion of public affairs is tolerated and even actively promoted by the Chinese state. Chinese public officials are using online discussion as a means to obtain feedback concerning the policies and goals of the government (Hartford 2005, Jiang and Xu 2009) and to monitor and control the actions of local officials (Hassid 2012). The Chinese state is actively building and promoting public deliberative forums on which it invites citizens to provide feedback and make policy suggestions. Someone who does not closely follow China's Internet scene might be very surprised to learn about some of the comments people are allowed to post, covering a 
range of topics including local corruption, the environment, or financial policies (MacKinnon 2012).

At the same time, the state also builds structures that function as a "safety belt" to control the content of the discussion and guide it in a direction supportive of the goals and policies of the authoritarian rulers, if necessary. China has built an extensive system for Internet surveillance and manipulation. This system includes configuration of Internet gateway infrastructure (Boas 2006), blocking websites and filtering (Chase and Mulvenon 2002), Internet policing (Brady 2008), regulation of Internet service providers (MacKinnon 2009), and suppression of dissident use and discipline of cyber cafes (Chase and Mulvenon 2002; Qiu 2000). As the state is clamping down on online public opinion, Internet users have grown savvy at expressing themselves through political satire and ironic uses of politically correct language to subvert controls (Yang 2009; Esarey and Xiao 2008).

Increasingly, the Chinese state has moved away from using coercive means and toward using softer means of control. While media companies are embedded into the state infrastructure, censorship is in practice outsourced to companies and users (MacKinnon 2012; Morozov 2011). An army of web commentators disguised as ordinary netizens shape and alter online public discourse (Bandurski 2008). Under Xi Jinping, party and state units have been building online portals and apps that encourage users to connect to an emerging e-governance system. In doing so, the state is occupying space for online discussion and coopting online public opinion (Han 2015).

While most of the discussion of the Chinese Internet has focused on the ways in which the Chinese state directly shapes and manipulates cyberspace, here we focus on subtle ways that seem apolitical on the surface but have important consequences for politics. While traditional media assume communication between a sender and a receiver, the Internet is by definition interactive. The interactive features of social media platforms structure public discourse and facilitate the development of online opinion in different ways. Taking an inductive approach, we conducted semi-structured interviews with twenty academics and product managers of the social media companies Tencent, Weibo, and Baidu between January and May 2015. Drawing on insights from these experts, our main aim is to conceptualize the structures shaping the expression of opinions on public affairs, which we refer to as online public opinion. By comparing Weibo, WeChat, and Baidu Tieba as the three most popular social media in China, we demonstrate that social media are created with a business goal in mind, but optimizing the platform toward one general core function creates an environment that fosters certain kinds of political behavior. We then hypothesize and provide preliminary evidence from 92 semi-structured interviews with Internet users that the Twitter-like Weibo has the potential to directly challenge state autonomy over information and therefore facilitates the rise of information cascades most strongly, while Tieba and
WeChat's potential concentrates on aiding in the formation of opinions and incubating issues that may then be disseminated via other social media platforms. Social media provide opportunities for politically motivated users to capture the platform for political purposes. Where and when public opinion forms and spreads in Chinese cyberspace has important implications for the pressure the Internet exerts on policymakers.

The Chinese state outsources the design of these interactive features to commercial companies, which by definition makes politics harder to detect, but by investigating the incentives built into the design, we tease out their relevance for information processing and the expression of opinions about public affairs. These incentives are intended to increase profit, but have unintended consequences for the development of online public opinion. Political considerations enter the design of social media platforms indirectly as commercial companies anticipate how technological designs fit with the broader strategy toward managing online public opinion.

\section{INFORMAL POLITICAL TALK AND ONLINE ACTIVISM}

Most social media are designed for other purposes than for political talk; in practice, however, many users use digital technology to share news, post political messages, and comment on issues of relevance to public policies. While most scholars would likely agree that attention to news does not constitute participation per se, political discussion or talk occupies something of a "gray" area. For example, Delli Carpini, Cook, and Jacobs (2004) argue that political discussion constitutes "sharing of public life"; informal talk about politics becomes a political act (Bennett, Flickinger, and Rhine 2000; Pan et al. 2006). Vegh (2003) proposes that there are progressive steps of online activism, ranging from seeking and disseminating political information and opinions to more radical forms of direct action such as hacktivism. Similarly, a growing body of research on online public opinion in China regards the expression of political views online as online activism. For example, in 2009 the Chinese Academy of Social Science published a report on the growing challenge of online activism in China. This report identifies a "new opinion class" made up of netizens who are concerned with news and current affairs. These netizens express their opinions online and "gather consensus, transform emotions, induce action and influence society within a very short period of time" (Xiao 2011, 221). Online activism in that sense is defined as the expression of an opinion on public affairs and participation in online political discourse. In the context of the Internet the boundaries between political talk and public opinion are blurred.

In this discussion about the rise of online public opinion in China, we see a return to an earlier scholarly discussion 
that described the nature of public opinion as a mode of communication. Today, public opinion is commonly regarded as the aggregate of individual attitudes within a particular social group whereby each individual's attitude is weighted equally (Converse 1987). Yet, before polling and surveys became the predominant form of measuring public opinion, researchers often described public opinion as a communication process, blurring the boundaries between public opinion and political participation. Allport (1937) noted that public opinion requires the verbalization of opinions on an issue widely known to a group of individuals and that public opinion represents an action or a readiness for action by individuals who are aware of others reacting to the same situation. Davison (1958) described the rise of such public opinion as a process that starts with the incubation of an issue in small group discussion and the emergence of leadership that formulates and spreads the issue, influencing the attitudes and behaviors of others. Through intergroup communication it becomes known by a large number of people, whereby the issue becomes public. A large number of people start to discuss the issue and form their own opinion and adjust their behaviors based on expectation of others' opinions and behaviors. While they may set the agenda in the process, they may also influence public opinion by framing, priming, or persuading others. In response, they might or might not take other political actions in order to change policies. Much like Blumer (1948), Allport (1937) and Davison (1958) understood public opinion as part of sociopolitical processes, mirroring the organization of society into social groups.

Interpersonal social networks play an important role in the formation of an issue and the transmission of the issue to a large number of people. Within social networks, acquaintances, corresponding to weak ties, are essential to exchange important information (Granovetter 1973), because people tend to know roughly the same as their friends, corresponding to strong ties. At the same time, trust and loyalty experienced in strong ties have the power to exert social pressure and motivate people to become politically active (della Porta 1988; Klandermans and Stekelenburg 2013). In a closely knit network, people may choose to express encouragement or approval in order to motivate friends (Coleman 1990; Flache and Macy 1996). Messages can spread quickly and become viral starting in strong and weak social networks (Lotan 2011).

Opinion leaders or influencers play a strong role in the emergence of information cascades, as suggested by Davison (1958). A very small number of people who are highly connected to others serve as hubs to spread information (see, for example, Gladwell 2002). Those opinion leaders generate information cascades online, but more sporadically than is commonly believed. Newer and less influential users can cause breakouts because of the subject matter, topic, timing, format, and trustworthiness of the message (such as video, image, news story, or petition) (see, for example, Bakshy et al. 2011; Goel et al. 2016; Lotan 2012). Overall, the emergence of information cascades is highly unpredictable.

Mass communication has the advantage of expediting information exchange and intergroup communication (Davison 1958). The so-called "social affordance" literature is concerned with the role of digital technology in changing people's communication behavior. Researchers have convincingly shown that the Internet fosters the maintenance of multiple communication streams with more diverse and geographically distant people (Boase et al. 2006; Wellman 2001). Different authors suggest that the Internet is conducive to the development of weak ties that provide opportunities for people to expand disparate friendship and organizational networks (Best and Krueger 2006; Hampton 2003; Haythornthwaite 2002; Kavanaugh et al. 2005). These features facilitate the emergence of information cascades in comparison to offline social networking.

We build on this discussion by specifying the technological settings that create environments facilitating or hindering the emergence of online public opinion. Research on political talk in small groups has demonstrated that the circumstances within which discussion takes place have a strong influence on online public opinion (see, for example, Delli Carpini, Cook, and Jacobs 2004). Governments relying on participatory forms of governance for political decision-making strategize about how to best organize and manage political discourse in deliberative settings (see, for example, Lodge and Wegrich 2015). Because rational argumentation, consideration of multiple viewpoints, and respect between participants are by most scholarly accounts rare on the Web, some online deliberative technologies have emerged that are specifically designed to foster deliberation deemed to be conducive to democracy (see, for example, Freelon et al. 2012).

Our first contribution in this article is to specify the interactive features of the technological design in social media platforms that may facilitate or hinder online public opinion. Most observers would agree that online public opinion originates in social media settings that are designed by commercial companies. Users are paying for the service of social media companies by providing the company with their data created by the use of the service, which directly translates into commercial income for the company. As a result, incentives are built into the design of social media platforms to increase the number of users and their level of engagement. It is important to understand which incentives companies aim to maximize when developing digital social technology and how these create incentives to contribute to online public opinion.

Our second contribution is to expand our understanding of the actions that contribute to online public opinion. In the discussion on information diffusion in digital social 
networks, scholars have focused on easily observable measures, such as retweets and likes (Cebrian, Rahwan, and Pentland 2016). Yet simply forwarding a message does not necessarily imply that a person agrees with the political message. Instead, users express political views, such as posting an original tweet, commenting on a message, and forwarding a message with a comment. In addition to these actions aimed at expressing opinions online, we also focus on actions taken to engage more deeply with online information, such as searching information as well as close reading as opposed to simply skimming text. Compared to similar offline behaviors, these actions gain greater participatory quality in the online environment: "For news consumption, the greater opportunities available in the online sphere for individuals to seek out sources and share them with others may also be leading to an 'upgrading' of this mode of engagement into a more active participatory form" (Gibson and Cantijoch 2013, 704-14). Such greater awareness and reflection also contributes to the rise of public opinion, as understood by Allport (1937) and Davison (1958), though ultimately attitudes only become part of online public opinion once they are expressed via text, images, audio, or video files, creating content.

To show how technological design facilitates actions aimed at deepening engagement with political information (searching information, skimming text, close reading of text) and at expressing opinion (posting, commenting, forwarding with comments), we focus on social media that are most likely to contribute to the rise of online public opinion. Next we explain which spaces for online public opinion exist in Chinese cyberspace and why we decided to focus on WeChat, Weibo, and Tieba.

\section{CHINESE SOCIAL MEDIA AND SPACE FOR ONLINE PUBLIC OPINION}

Social media allow users to connect, communicate, and interact with each other, often by posting, sharing, or co-producing information (Correa, Hinsley, and Zúñiga 2010). These two functions - social interaction and information-sharing - are at the core of social media. We classify spaces for online public opinion in Chinese cyberspace according to two dimensions. The first dimension relates to the degree to which individual users or formal organizations, such as traditional media outlets or state or party institutions, distribute information on the site. The second dimension depends on how much reciprocity between users supporting interactive conversation between users, as opposed to one-dimensional conversation from a sender to receivers, the platform allows. Space for online public opinion can be mapped onto a two-dimensional construct of social media (Figure 1).

In this two-dimensional space, news websites belong to the bottom left, as journalists and editors of news websites disseminate information as part of an organization. While websites often allow users to comment on articles, users usually do not interact with each other when commenting; instead, the conversation is primarily between the news agency as the sender and the user as the receiver, with some opportunities to give feedback.

Wikipedia-like websites, such as Baidu Baike, the Chinese version of Wikipedia, are located at the bottom right, since all content on this type of websites is generated by users. The similarity between Wikipedia-like websites and news online portals is that they have limited features for users to interact directly with each other. On Q\&A websites, such as Baidu Zhidao and Zhihu, users generate questions

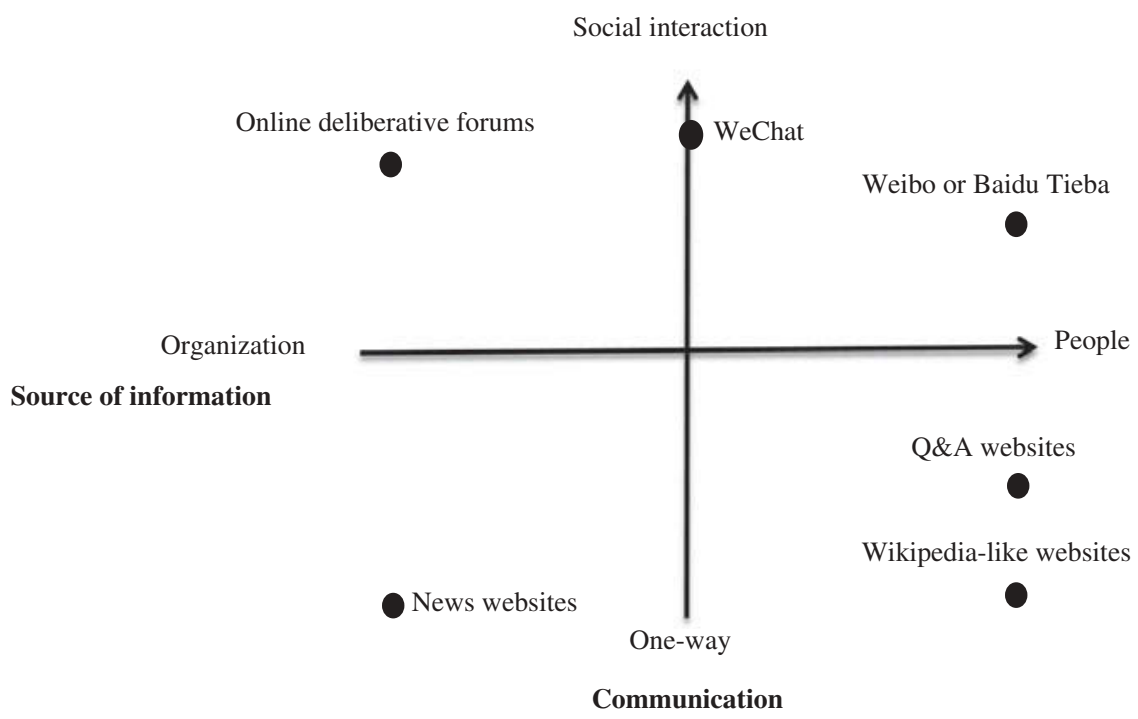

FIGURE 1 The two-dimensional mapping of various Chinese online media. 
and answers; they can also comment and rate answers or provide a better answer, which allows some levels of interaction between users. As such, these websites are also located at the spectrum on the right but offer more reciprocity between users than Wikipedia-like websites.

At the top left spectrum, we locate online deliberative forums organized by governments or social organizations. Especially, local governments utilize online space for public hearings to obtain citizens' feedback and complaints about policies (see, for example, Zhang 2015). These online deliberative meetings are organized by organizations and participants are allowed to input their opinions directly onto the forums.

The top right of Figure 1 is the space for political discussion we are most interested in, because most messages that become viral originate here, according to our interviews. These social media platforms support reciprocal conversation between users and offer users at least some opportunities to become the source of information. Among those sites, we focus on Sina Weibo, Baidu Tieba, and WeChat as the three social media platforms with the largest user base in Chinese cyberspace. ${ }^{1}$

Sina Weibo was initially a Chinese Twitter but later started to incorporate more Facebook-like social features. ${ }^{2}$ Weibo is the only vibrant micro-blogging platform nowadays in China, with 175.7 million monthly active users. ${ }^{3}$ Baidu Tieba is a BBS-like chat forum with an average of 50 million new posts posted per day. ${ }^{4}$ WeChat, developed by Tencent, is the most popular instant messenger in China, with 500 million monthly active users. ${ }^{5}$ In contrast to QQ, the other popular instant messenger developed by the same company, WeChat is a mobile phone-based app. As such, these three social media platforms provide three of the largest spaces for informal political discussion in Chinese cyberspace.

Weibo, WeChat, and Tieba vary in terms of the two dimensions of online media. The Twitter-like Weibo offers anyone the power to become the source of information, including users and organizations, particularly traditional media outlets. On Tieba, users are able to set up their own group and attract other users who share similar interests by sharing information. WeChat, on the other hand, emerged as an instant messenger and therefore allows for a high degree of social interaction between users, which can be in various formats (namely, text, audio, video or picture) and in various settings (one-to-one or group chatting). In addition to the instant messenger, WeChat also has a Facebook "wall" called "Moments" that allows users to post content. But, only links created by WeChat public accounts, various online websites, or mainstream media accounts can be shared. In order to generate public information that can be shared on Moments, users need to open a public account, which is open to both organizations and individuals. As the platform facilitates a more formal organization of users into public accounts, it is placed more toward the left spectrum than Weibo and Baidu Tieba.

\section{BUSINESS GOALS AND INCENTIVES BUILT INTO SOCIAL MEDIA PLATFORMS}

The Chinese state outsources the design of social media to commercial companies, which makes politics by definition harder to detect. In our conversations we focused on interactivity as the defining characteristics: social media allow users to communicate and interact with each other, whereby information (content and data) is generated. ${ }^{6}$ This language allowed us to tease out key features of technological design that have unintended consequences for online public opinion.

Social media companies have a great incentive to increase interactivity, because interactivity is their source of revenue. Most Chinese social media companies are based on business models that generate income by using their data to target advertising. ${ }^{7}$ The greater the data set of users and the more active the users, the larger the income and potential profit for the social media company. ${ }^{8}$ As one senior product manager put it, "Increasing number of users, increasing level of influence, ${ }^{9}$ and increasing amount of revenue generated are the three key purposes for every social media product."

Because of the commercial rationale for designing technology that increases the level of interactivity, product managers designing the social media product start by drawing on market research to understand the users' needs and demands. ${ }^{11}$ In his response to the question "What feature is most important to interactivity," an Android app designer commented: "The most important point ... is how to make the feature satisfy users' emotional need. It may be the need to compete with others and to win. This emotional need is always there, but the question is how to trigger this need of users or how to gratify users' vanity."12 Such user needs can range from social needs, such as, for example, attracting others' attention, gaining respect, being envied by others, competing, and sharing, ${ }^{13}$ to information needs, such as, for example, seeking information or knowing people who share similar interests. ${ }^{14}$ Other social media also seek to be fun to play with and to satisfy entertainment needs of users. ${ }^{15}$ Because we focus on social media that play an important role in online public opinion, the needs that social media experts identified as central to WeChat, Weibo, and Tieba are seeking information, strengthening knowledge and understanding, and gaining respect, as well as social needs to develop and maintain social networks.

Social media experts emphasize that product managers make a choice as to which user need to concentrate on when designing the platform. We call those the platform's core functions, which are linked to user need. For example, a market researcher at Weibo explains that Weibo is maximized toward making people into the source of information; therefore, interactive technology strengthens information needs on Weibo. ${ }^{16}$ In contrast, WeChat was designed to maximize the maintenance of intimate social interaction between friends, family, and acquaintances, satisfying social needs. ${ }^{17}$ Tieba focuses on bringing people with similar interests together 
and promoting discussion within each interest group, which places information needs at its core. When designing technology, this core function forms the standard according to which the company invests resources to develop the platform and in terms of which the company measures its success in attracting users and keeping them engaged with the platform. ${ }^{18}$

These examples reveal the commercial rationale behind technological design. None of the social media platforms we focus on here are built with a political purpose in mind, but instead are intended to satisfy certain user demands, broadly defined. Below we uncover how the incentives built into the technological design of WeChat, Weibo, and Tieba facilitate or hinder political engagement and expression as one unintended way in which users use social technology. To uncover these incentives, we talked to social media experts about the platforms' interactivity.

\section{INTERACTIVE DESIGN OF WEIBO, WECHAT, AND TIEBA}

Interactivity served as a way for us to discuss politics with project managers in an apolitical way. Building on research by Sally J. McMillan and Jang-Sun Hwang (2002), we asked social media experts about a platform's responsiveness to messages and control of the user over the communication. These elements of a platform's interactive technological design enable us to assess how the platform structures the communication process. Responsiveness and user control aim to strengthen the platform's core function. According to social media experts, responsiveness captures the timely and correct responses users receive either from the system or from other users, while user control offers users a sense of control over the social media platform and the ability to perform certain tasks in line with the core function. ${ }^{19}$ Next we explain how responsiveness and user control figure into the structure of communication on WeChat, Weibo, and Tieba, according to our interviews.

\section{User Control}

User control manifests itself in terms of choices that users have over the social media platform (e.g., Laurel 1986, 1997). Weibo originally copied most of the choices for users from Twitter, but has added additional choices to its original design to accommodate trends related to its core function. These choices are always made based on considerations regarding whether they help users to become the source of information and to manage the information they receive. Weibo has a 140-word limit on tweets, enabling fast dissemination and consumption of key information, while also allowing users to attach long articles to a post in order to better integrate bloggers as new sources of information. ${ }^{20}$ Users also can post pictures in their comments in order to share information. ${ }^{21}$ Most importantly, Weibo users can group the accounts they follow and view information by these groups. From the Weibo manager's point of view, ${ }^{22}$ this function is crucial for its core function as it helps to reduce the information flow for users, which tends to be massive on Weibo. This function, technically speaking, is not difficult to develop. But both WeChat and Baidu Tieba do not have this function, because seeking information is only a secondary feature for WeChat, while information is always contained and grouped within interest groups on Baidu Tieba (see Table 1).

Compared to Weibo, Tieba focuses on seeking and generating information within interest groups, which manifests itself in two key user choices, according to one Tieba product manager. First, any user of Tieba can form a group and become a group administrator in charge of managing a group. Second, Tieba offers a unique design called "mezzanine floor comment structure" (see Figure 2). In architecture, a mezzanine floor is an intermediate floor between the main floors of a building and is not counted as a floor. On Tieba it refers to all replies to a comment appearing underneath a comment, instead of the original post; and these replies are part of the comment they

TABLE 1

Level of Interactivity of Weibo, WeChat, and Baidu Tieba on User Control

\begin{tabular}{|c|c|c|c|}
\hline & Weibo & WeChat & Baidu Tieba \\
\hline Core function & $\begin{array}{l}\text { Users as the source of } \\
\text { information }\end{array}$ & Promoting intimate social relationships & Finding interest groups \\
\hline Seeking and generating information & $\begin{array}{l}\text { - Users can post content in } \\
\text { various formats including } \\
\text { long articles in addition to } \\
\text { the } 140 \text {-word tweets. } \\
\text { - Users can post pictures in } \\
\text { comments. } \\
\text { - Users can group accounts } \\
\text { they follow and view infor- } \\
\text { mation by these groups. }\end{array}$ & $\begin{array}{l}\text { - Users need to set up public accounts in } \\
\text { order to generate information that can } \\
\text { be disseminated. } \\
\text { - Anyone can set up a public account, but } \\
\text { each public account is allowed to post } \\
\text { once per day, regardless of the number } \\
\text { of articles per time. }\end{array}$ & $\begin{array}{l}\text { - Users can form groups and become the } \\
\text { group administrator. } \\
\text { - Through the "mezzanine floor comment } \\
\text { structure," users can easily engage in } \\
\text { discussion of sub-topics and create } \\
\text { further division of groups. }\end{array}$ \\
\hline Social interaction & $\begin{array}{l}\text { - Chatting is a button at the } \\
\text { bottom right of the first } \\
\text { page, requiring one click to } \\
\text { open it. } \\
\text { - Limited chatting options. }\end{array}$ & $\begin{array}{l}\text { - Chatting is on the first page after log- } \\
\text { ging in. } \\
\text { - Various options to chat: text, voice, and } \\
\text { video. }\end{array}$ & $\begin{array}{l}\text { - Private message box is one option on } \\
\text { the top right of the first page, requiring a } \\
\text { few clicks to reach. } \\
\text { - Limited chatting options. }\end{array}$ \\
\hline
\end{tabular}




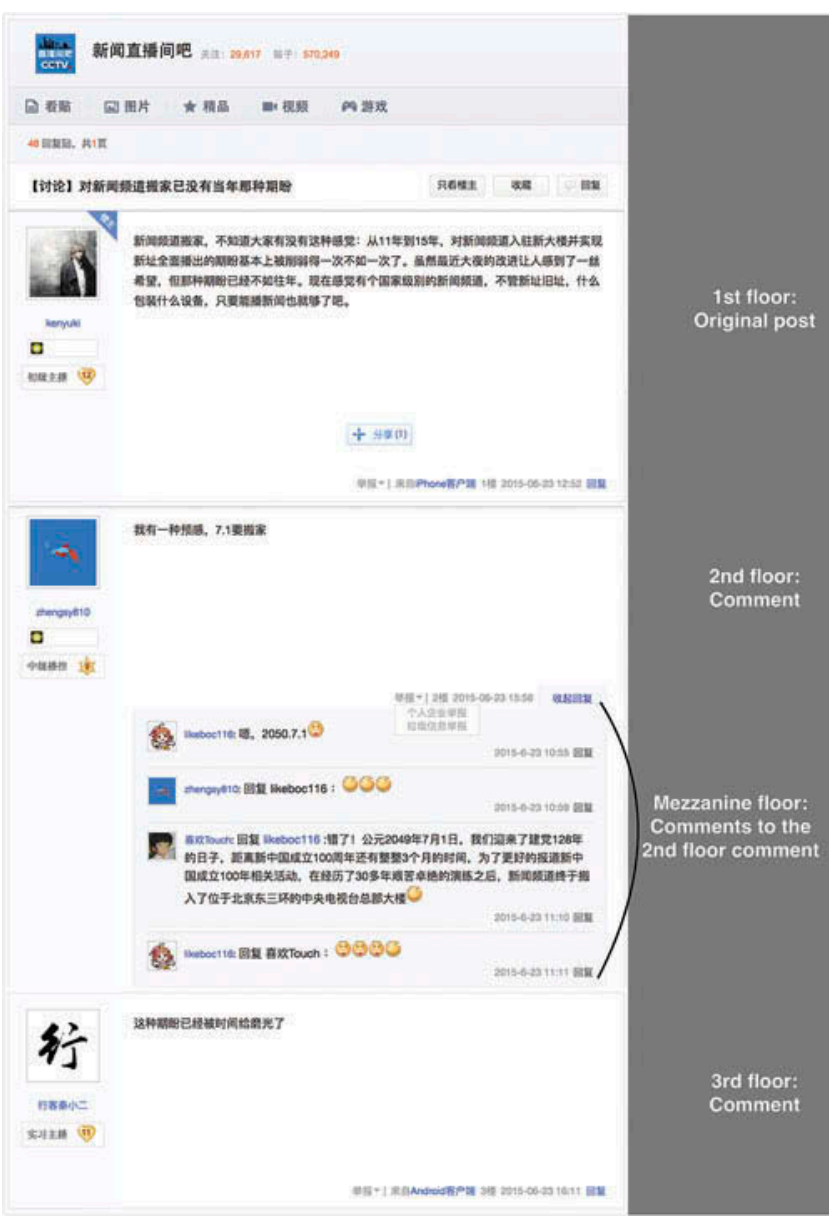

FIGURE 2 Screenshot of the "mezzanine floor comment structure" on Baidu Tieba (http://tieba.baidu.com/p/3845088799, accessed on March 17, 2017).

are linked to. This unique feature aims to promote discussion within interest groups and the development of subgroups and new interest groups. Users can leave the current group and form another new group based on shared interest.

In contrast to Weibo and Tieba, WeChat focuses on maintaining intimate social relationships. WeChat does this by offering users various options to chat, such as text, voice, and short video. As a very popular feature, users can record and send voice messages with a maximum length of one minute each. When using WeChat's instant messenger, users can create different groups and have group chats. Neither Weibo nor Tieba is able to compete with WeChat on this aspect. "I think Weibo realized the importance of social interaction and did develop some group chat functions before; but the products containing social interaction functions were not popular and failed in the end." ${ }^{, 23}$ On Tieba, users leave each other a QQ number or WeChat number if they want to contact each other outside of the Tieba platform. One Tieba product manager admitted that the social interaction feature is not Tieba's strength, but added, "We should just continue with the current division of labor and do what we are good at.",24
WeChat has limitations built into information sharing, which mostly takes place via public accounts on Moments. WeChat users gain access to public accounts via subscription accounts (订阅号, Dingyuehao). “On Dingyuehao, the list of public accounts is folded and users need to click on the subscription accounts button to unfold the list. And each public account is allowed to post once per day, although there is no restriction on the number of articles each account can post per time. ${ }^{, 25}$ As a professor in new media explained, "WeChat does not want the user experience of social interactions to be interrupted by the dissemination of public information. $" 26$

Overall, a formal and structural organization of information is required for WeChat users if they want to generate information that can be disseminated. In comparison, Weibo and Tieba users enjoy more freedom to generate information, but the difference between Weibo and Tieba lies in whether information is organized based on the individual user or the interest of a group of users. WeChat offers users more options to interact with others socially.

\section{Responsiveness}

The relatedness of sequential messages is one important aspect of responsiveness (Rafaeli 1988, 111). With regard to social interactions, responsiveness is straightforward: "When you ask a question, someone will answer it; when you post a picture, someone will give you a thumb-up; when you express a terrible experience you had, someone will give you sympathy. This means that you can get what you want immediately." 27 WeChat's instant messenger offers real-time one-to-one communication and group communication and is therefore strong in this regard. If users wanted to engage in one-to-one communication or a small group chat on Weibo or Tieba, they usually move to an instant messenger, even though Weibo and Tieba also offer a private messenger as a feature, according to product managers. As an associate professor in media and communication explained, WeChat "users can communicate with others anytime and anywhere they want." ${ }^{28}$ WeChat provides more responsiveness between users under the setting for real-time communication.

Regarding information-sharing, however, WeChat is less responsive compared to Weibo and Tieba. In forwarding, the relatedness of sequential messages is largely maintained on Weibo: users can forward posts along with any picture, link, or video and subsequent comments about the original post by others, as long as the post does not exceed the 140word limit. Tieba, on the other hand, uses the "mezzanine floor comment structure," which categorizes messages and replies about the same issue into one group and increases the relatedness of sequential messages. ${ }^{29}$ On WeChat, however, only links created by WeChat public accounts, various online websites, or mainstream media accounts can be forwarded, and the comments about the links by users' 
contacts cannot be shared unless users manually copy and paste the comments to the new posts.

Another important aspect of responsiveness is how responsive the system is to the preferences set by the user. As a marketing researcher of a social network site in China mentioned, ${ }^{30}$ Weibo and Tieba both deliver posts that match the user's interest, while on WeChat Moments, posts are ordered in chronological order, and on the subscription accounts of WeChat, users just get what they subscribe to. WeChat does not, for example, recommend public accounts that match user's interest.

The final aspect of responsiveness is the speed of information delivery. Public account users on WeChat are allowed to post once per day, regardless of the number of articles posted per time. In other words, information on public accounts of WeChat is only updated once per day. On Weibo and Baidu Tieba, there is no such restriction and users can post as often as they want. Therefore, information is more up to date on Weibo and Baidu Tieba.

As can be seen in Table 2, on seeking and generating information, Weibo and Baidu Tieba are more responsive in that they maintain the relatedness of sequential messages, are responsive to a user's preference when delivering information, and allow timely delivery of information. Tieba arranges information according to topics, while Weibo arranges information according to users. ${ }^{31}$ WeChat, on the other hand, is more responsive on social interactions by allowing users to chat in real time.

\section{Privacy Settings and Social Networks}

As mentioned earlier, existing literature on social media has mostly focused on how the structure of social networks within social media platforms contributes to information diffusion and public discourse taking place. Although our focus here is on responsiveness and user control it is also helpful to explain how digital technology manages the structure of social networks via its public and private settings (See Table 3).

Due to its emphasis on close ties in small groups, WeChat restricts access to information based on the user's contacts. Information on Weibo and Tieba, however, is accessible to any user of the platform. On Weibo, a user can view posts by other users regardless of whether they are friends with each other or not; unless a user sets restrictions on who can view the posts, what the user posts is accessible to any user on Weibo. The difference between Weibo and Baidu Tieba is where information is located: information posted on Tieba can be found within each interest group, while information posted on Weibo is on each user's own page. Similarly, on WeChat, users can only interact with their contacts, while on Weibo and Baidu Tieba, users can interact with any user on the platform.

Decisions about which information remains private and which is accessible to the public are closely linked to the social networks of the platform: "WeChat is like a living room and Weibo is like a square ...: [on a public square] everyone can voice their opinions regardless of whether they know each other, while you will only invite people who you know to your living room." 32 Tieba is a place where people can find others with similar interests; discussions are arranged according to themes of interest and thus contained within each discussion forum. As such, Tieba is like a workshop for those who are interested in the topic and others are free to join. ${ }^{33}$

\section{INTERACTIVITY AND ONLINE PUBLIC OPINION}

How do responsiveness and user control relate to the rise of online public opinion? Here, we offer some preliminary evidence based on qualitative interviews with 92 users,

TABLE 2

Level of Interactivity of Weibo, WeChat, and Baidu Tieba on Responsiveness

\begin{tabular}{|c|c|c|c|}
\hline & Weibo & WeChat & Baidu Tieba \\
\hline Seeking and generating information & $\begin{array}{l}\text { - Users can forward posts with any picture, } \\
\text { link, or video and subsequent comments } \\
\text { about the original post by others, as long } \\
\text { as it does not exceed the } 140 \text {-word limit. } \\
\text { - System delivers posts or contacts that the } \\
\text { user may be interested in. } \\
\text { - Information can be delivered at any time } \\
\text { and in various formats and thus is fre- } \\
\text { quently updated. }\end{array}$ & $\begin{array}{l}\text { - On Moments, comments by contacts can- } \\
\text { not be shared. } \\
\text { - System orders posts on Moments in } \\
\text { chronological order with the most recent } \\
\text { ones on top. On subscription accounts of } \\
\text { WeChat, users just get what they sub- } \\
\text { scribe to. } \\
\text { - On public accounts, each public account } \\
\text { is allowed to post once per day and thus } \\
\text { information is updated less frequently. }\end{array}$ & $\begin{array}{l}\text { - The "mezzanine floor } \\
\text { comment structure" } \\
\text { arranges replies accord- } \\
\text { ing to discussion topics. } \\
\text { - System delivers the top } \\
\text { posts that match the } \\
\text { user's interest. } \\
\text { - Users can post any time } \\
\text { as they want. }\end{array}$ \\
\hline Social interactions & $\begin{array}{l}\text { Private chatting box is perceived by experts } \\
\text { as a failure in promoting real-time } \\
\text { communication. }\end{array}$ & Real-time chatting available. & $\begin{array}{l}\text { Private message box } \\
\text { functions more like an } \\
\text { email box; not } \\
\text { convenient for chatting. }\end{array}$ \\
\hline
\end{tabular}


TABLE 3

Privacy Settings of Weibo, WeChat, and Baidu Tieba

\begin{tabular}{llll}
\hline & Weibo & Baidu Tieba & WeChat \\
\hline Access to information & Anyone & Anyone & User's contacts \\
Access to social interaction & Anyone & Anyone & User's contacts \\
\hline
\end{tabular}

varying in terms of gender, education, age, and region. Interviews with Internet users were conducted over two periods-between January and May 2015 and between October 2015 and March 2016. ${ }^{34}$ In our semi-structured interviews we asked users how they used WeChat, Tieba, and Weibo in order to talk to each other or share information regarding politics. ${ }^{35}$

As explained earlier, when a concern or problem emerges, the issue is first discussed in a group that is hospitable to it (Davison 1958). When discussion takes place on WeChat's instant messenger, the platform can contribute to incubating an issue. A few interviewees explained that when they find interesting news or information on WeChat, they prefer to share it with their friends one-to one or within a group chat, instead of sharing it on Moments. $^{36}$ Because WeChat structures communication within close networks, users express hesitation to voice and discuss politics on Moments.

For example, a female interviewee explained that she recently posted an original post about her positive views of homosexuality on WeChat Moments, where she was cautious to express her view implicitly in the context of a movie called Blue Is the Warmest Color, a love story between two females. ${ }^{37}$ Instead of expressing her view directly, she related the movie to an influential television program in China called Weirdo Talk, $^{38}$ in which mainstream views are challenged, and wrote about the social implication of such movies and shows. "I have relatives, friends, and colleagues from work on my WeChat contact list, and I have to anticipate that all of them will see what I write. I need to keep this in mind when I write."39 Asked whether she was receiving the sort of comments she expected, she replied: "There were very few comments and not a single one joined the discussion. Even those few comments were social comments, such as liking the post, or saying your new profile picture is beautiful, or comments like 'homosexual movie?'. But none of my contacts engaged in discussion about the movie, about the social implications of the movie, or about the development of Chinese society." 40 She felt that comments and responses on WeChat are held hostage to social politeness - that is, a person responds "not because I feel passionate to do so, but because I feel like I should." the social politeness induced by WeChat's focus on social interactions between contacts, many interviewees perceive WeChat as a tool for social communication and interactions, a perfect substitute for the mobile phone message function, ${ }^{42}$ but not for voicing and disseminating opinions. ${ }^{43}$
Tieba, by contrast, serves as an issue incubator for public opinion. The ability of individual users to set up their own interest groups and the unique "mezzanine floor comment structure" facilitate the formation of issue publics. People who find out that they share similar views about an issue can set up their own subgroups and continue further discussion about the issue. Facts and opinions about the issue concerned can be fully discussed and revealed in such a group setting. Although Tieba is not designed for the purpose of discussing politics, the group structure enables heated discussion regarding any issues, including political ones, and facilitates the formation of common opinions within the group. ${ }^{44}$ In addition, setting up and managing a new group on Tieba inevitably leads to the formation of a group structure and group leadership, which facilitates the emergence of leadership at the issue-formation stage. ${ }^{45} \mathrm{~A}$ male Weibo and Tieba user explained the difference between the two platforms as follows: "On Tieba, we gather together because we all like, let's say, a particular super star, and we get to know all the information about him and activities organized to support him. And members can interact with each other, which Weibo does not have. I mean that members can comment underneath the main post and there is mezzanine floor comment structure that we can even interact underneath a comment." 46 On Tieba he has a sense of belonging to a group that has a structure and whose members share common interest, while on Weibo he does not have this sense of belonging. The sense of belonging to a community or group is conducive to the discussion and formation of opinions (Klandermans and Stekelenburg 2013). For an issue to survive, to develop, and to disseminate, small groups need to be hospitable to the issue (Davison 1958) and act as "a radiating nucleus for an idea" (Lasswell 1930, 187).

As compared to Baidu Tieba and WeChat, Weibo offers users the power to be a source of information. It lacks the group structure that can facilitate discussion of an issue during the incubation stage, yet, it is the key venue for discussion about an issue to transit from small groups to become a topic for inter-group communication. In other words, Weibo can turn an issue discussed in small groups into a public issue. Several features of Weibo facilitate this process. First, users have a wide range of choice over the format of posts, and this facilitates the fast production of information about the issue concerned in breadth. Second, relatedness of sequential comments on Weibo facilitates the discussion of the issue concerned in depth. Last but not least, Weibo is accessible to the public and thus it is possible to raise awareness of the issue among a large number of people. The male interviewee mentioned above also pointed out the ability of Weibo to turn an issue into a public issue: "Information can spread very quickly [on Weibo]. For example, as far as I know, most information about corruption and other negative news emerges as discussion topics on Tieba; but this information can be shared and forwarded 
by a significantly larger audience in a very short time through Weibo.... [On Weibo, for example] I want to record an issue or publish a piece of news; and others might have seen it and forwarded it; and this chain of forwarding the post can go from one to ten, from ten to a hundred, and then from hundreds to thousands of people. At the end, everyone knows the issue. This is one reason why many people are still using Weibo." ${ }^{\text {"47 }}$ In other words, the ability of Weibo to allow dissemination of information and opinions to a large number of people in a fast manner is a key selling point of Weibo, from the user's perspective. The forwarding feature on Weibo, as distinct from WeChat, contains sequential comments about the original link or post, allowing the dissemination of opinions, so that users get to see how an idea is developed.

Compared to WeChat, Weibo offers greater publicness, but it does not discourage political communication as WeChat does on its Moments. This has to do with the social networks created by the public and private settings of the social media platforms. In a public venue, the majority of the audience a speaker faces are strangers, while in a living room a speaker faces visitors who know the speaker personally. As one interviewee put it: "Because [on Weibo] strangers don't know who I am, I don't care what they might think of me; it's different on WeChat Moments, where everyone knows who you are." 48

After an issue has been posted on Weibo, people might circulate the information back to their social groups on WeChat or Tieba, but the difference at this stage is that the issue has become a public issue and is discussed in many small groups instead of few groups at the issueincubation stage. Thus, Weibo serves as a key venue that brings the issue to the attention of a wider audience and fosters inter-group communication.

\section{CONCLUSION}

In the debate about the role of social media in authoritarian states, cyber-optimists and cyber-skeptics have so far focused on ways in which states censor and manipulate this content, and ways in which users may undermine state control. Instead of state regulations and the content of online discussion, here we have focused on interactivity in order to explore the various structures for political discussion that are created by the technological design of social media companies. This is an important dimension specific to the Internet which facilitates certain kinds of actions taken by users while limiting others. By comparing Weibo, WeChat, and Baidu Tieba as the three social media with the largest user bases in China, we have discovered that information technology (IT) companies aim to attract specific kinds of users by satisfying one very specific demand that users have, such as spreading information, finding people with common interests, or sustaining intimate relationships.
Every interaction the user has with the system or with other users is optimized toward this one core function. Core functions are kept as general as possible to attract a large and active user base, as a large and active user base directly translates into profit for the IT company. Social media are therefore rarely created with a particular political purpose in mind.

While Weibo clearly has the greatest potential to facilitate the rise of online public opinion on politically relevant topics, we should not underestimate the potential of WeChat and Baidu Tieba for incubating issues and forming opinions that are essential for public opinion to rise and for mobilizing collective action. The group structure of Baidu Tieba is conducive to the discussion of issues among people sharing similar interests, and the formation of opinions. The maintenance of groups on Baidu Tieba also inevitably leads to the emergence of leadership, which is also crucial for the rise of public opinion. But, given that Baidu Tieba is arranged according to interest, some interest groups are far more likely than others to stimulate public opinion formation, especially those that deal with subjects of public interest, such as health-related groups. Although WeChat places restrictions on generating and disseminating public information, its social interaction feature strengthens social bonds among people who already know each other. Its real-time chat remains a powerful venue for people to disseminate information, discuss issues, and incubate opinions more privately, in small groups. While both are limited with respect to their ability to organize around political issues, there are also possibilities. Baidu Tieba limits the creation of groups based on what are considered politically sensitive topics, but politics may pop up as a topic in groups that are organized around a non-political interest. WeChat's real-time chat can help to address coordination problems, although there is a restriction imposed on groups with more than 100 members. For those larger groups, each member is obliged to link their WeChat to a Chinese bankcard in order to join the group. In other words, members of large group are required to register with their real identities. While this makes it harder for outsiders to observe political use, as compared to the public forum Weibo, these social media still provide opportunities for users with political motives to capture the platform.

Social media companies in China are aware of the possibility that some users may capture social media for a political purpose. However, they are also aware that social media differ in terms of their potential, depending on the design. Among the three social media we study here, Weibo is the only one that directly challenges state autonomy over information, as it is designed to empower users to become an information source and to spread information online in a public forum and across social media platforms. Not surprisingly, when asked which social media facilitate online public opinion best, most 
interviewees state that no Chinese social media do that except one: Weibo. ${ }^{49}$ Sina was able to create such a platform because it could sell the idea that Weibo would facilitate the guidance of online public opinion by imposing a certain structure onto the discussion. An analysis of online discussion on Weibo about an issue, for example, can help Renmin Net to find a way to construct a positive post that guides online discussion toward the direction favored by Renmin Net. ${ }^{50}$ Thus, Weibo could both serve a commercial purpose and simultaneously aid in guiding public opinion. Similar arguments are frequently made by traditional media outlets that have to simultaneously serve the market and the state (see, for example, Zhao 1998; Lee 2000; Stockmann 2013). While social media are not created with a political purpose in mind, commercial companies seek frames that allow them to sell the concept of a platform to the regime.

In addition to working together with partners in order to actively shape online public opinion, social media companies also build politics into the technological design and management of content. Depending on the platform's potential to contribute to information cascades, different strategies of censorship and control are built into the platform. For example, on WeChat, it is difficult to spread information due to limitations imposed on the number of people who can be added to a group. For groups with more than 100 members, every member needs to link their bank account with their WeChat. "It is an act that requires you to submit some documentation. Why? Because small groups have no impact [while big ones do, and thus need to be registered]." ${ }^{51}$ In contrast, "authorities only need to make sure that they control the big Vs [on Weibo]," 52 as they are influential in spreading information and facilitating the rise of public opinion. Tieba is characterized by a phenomenon called "Baoba" (爆吧), which refers to users deliberately posting a massive amount of information within a short period of time. This happens frequently when two Tieba groups disagree with each other and continue to re-post information, using insulting language. The Tieba product manager drew an analogy of this phenomenon to protests: "In real life, when people have grievances, they may use protests as a means of expression, which is not allowed, and the police take care of that. Similarly, on Tieba, we have our rules and regulations [surveillance by machine or human being to detect that kind of activity on Tieba] to make sure that such activities do not ruin our user experience." 53 These strategies remain specific to the core function for which the platform was created.

Social media can be appropriated for political purposes, and companies develop strategies to collaborate with partners to actively shape online public opinion or build in limitations to prevent information cascades.
While companies do not openly talk about the political considerations informing digital intervention, it is likely that broader trends in the political climate do play a role when making decisions about product development. For example, the space for media reporting undergoes cycles of expansion and contraction depending on leadership cycles. Weibo emerged at a time when the $\mathrm{Hu}-$ Wen administration actively promoted public feedback mechanisms for policymaking, at a time when the space for media was relatively open, while WeChat emerged shortly before a leadership transition, when the space for media tends to tighten (Stockmann 2013). Despite these broader trends that may inform the decision-making of social media companies, we have not found evidence that the Chinese state actively intervenes and promotes certain social media platforms via regulations. It has been speculated that a crackdown on opinion leaders (so-called "Big Vs") on Weibo has diverted some users to WeChat. However, according to our interviews, ${ }^{54} \mathrm{Big} \mathrm{Vs}$ have become more cautious and voice their opinions less frequently as a result of the crackdown, which makes Weibo less a platform with opinion leaders at its core than a platform where content is mostly created by ordinary users. The crackdown had a stronger influence on content than on user numbers.

Overall, social media are primarily designed to attract a large and active user base. With one core function, social media can be appropriated for political purposes by users. Platforms like Tieba and WeChat will not take over the role of Weibo, simply because they were designed to satisfy demands that do not directly challenge the autonomy of the state over information. Despite the hidden politics in technological design, political considerations still enter the design of social media platforms as commercial companies anticipate how technological designs fit with the broader strategy toward managing online public opinion. By actively shaping and manipulating the broader information environment, the government can indirectly influence product design and facilitate digital innovation to foster the power of online public opinion or inhibit it.

\section{FUNDING}

The research leading to these results has received funding from the European Research Council under the European Union's Seventh Framework Programme (FP/2007-2013) /ERC Grant Agreement n. [338478]. The Hertie School of Governance and Leiden University are both beneficiaries of the grant. For more information on this project, entitled "Authoritarianism 2.0: The Internet, Political Discussion, and Authoritarian Rule in China," see www. authoritarianism.net. 


\section{NOTES}

1. QQ is another instant messenger designed by Tencent, just like WeChat. We chose WeChat, because it is frequently mentioned in the discussion about online public opinion in China and because of its growing user base; as of June 2015 WeChat had 600 million monthly active users and QQ 800 million. Interview with a marketing expert (73583), February 2015.

2. Interview with a Weibo product manager (75591), April 2015.

3. http://tech.sina.com.cn/i/2015-03-11/doc-iawzuney0631454.shtml, accessed on May 28, 2015.

4. Interview with a Baidu Tieba senior manager (72906), April 15, 2015.

5. http://tech.sina.com.cn/i/2015-03-18/doc-icczmvun6903718.shtml, accessed on May 28, 2015.

6. Interview with an Android app designer (77493), March 2015. Interview with a Weibo product manager (75591), April 2015.

7. Interview with a Weibo product manager (75591), April 2015. For a detailed explanation of how a user profile can be drawn with the user data, please see http://chuansong.me/n/696144, March 14, 2017.

8. A number of IT professionals we interviewed confirmed this link between interactivity and business interest among Chinese social media. Interview with a Weibo product manager (75591), April 2015. Interview with a Baidu Tieba senior product manager (72906), April 2015. Interview with an Android app designer (77493), March 2015.

9. Here, influence refers to an increasing number of active users and more actions performed by users, as the number of monthly active users has been used widely by social media companies to indicate their influence.

10. Interview with a Baidu Tieba senior product manager (72906), April 2015.

11. Interview with a product manager of a small social media company specialized in photo sharing (76465), April 2015.

12. Interview with an Android app designer (77493), March 2015

13. Interview with an Android app designer (77493), March 2015.

14. Interview with a Baidu Tieba senior product manager (72906), April 2015.

15. Interview with a marketing manager of a big social media company in China (73583), February 2015.

16. Interview with a Weibo marketing researcher (73359), April 2015.

17. Interview with a marketing manager of a big social media company in China (73583), February 2015.

18. Interview with a Weibo marketing researcher (73359), April 2015.

19. Interview with an Android App designer (77493), March 2015. Interview with a Baidu Tieba senior product manager (72906), April 2015.

20. Interview with a Weibo product manager (75591), April 2015.

21. Interview with a Weibo product manager (75591), April 2015.

22. Interview with a Weibo product manager (75591), April 2015.

23. Interview with a Weibo marketing researcher (73359), April 2015.

24. Interview with a Baidu Tieba senior product manager (72906), April 2015.

25. Interview with a Weibo product manager (75591), April 2015.

26. Interview with a professor in new media (75919), April 2015.

27. Interview with an Android app designer (77493), March 2015.

28. Interview with an associate professor in media and communication (72286), April 2015.

29. Interview with a Baidu Tieba senior product manager (72906), April 2015.

30. Interview with a marketing research of a social network site in China (79696), April 2015.

31. On Baidu Tieba, all replies to a comment appear as a part of the specific comment, while on Weibo, only when two persons continue to reply to each other underneath a post will the "view the communication" feature be available.
32. Interview with an associate professor in political science in China (75154), April 2015.

33. Interview with an associate professor in social psychology (71963), March 2015.

34. We selected interviewees using multiple entry points to decrease selection bias in snowball sampling. Among the 92 interviewees, 42 are male and 50 are female; 39 were students at higher education institutes. These students were selected from universities in Beijing, Changsha, Guangzhou, Tianjin, Xiamen, and Zhangjiajie. In terms of age, our sample consists of 54 interviewees younger than age thirty, 26 between thirty and forty-nine, and 12 between fifty and seventyfive. In terms of education, we have 59 interviewees with an education of college level or above. Apart from 6 interviewees residing overseas at the time of the interview, 86 interviewees were living in cities or rural counties of fifteen provinces or municipalities in China. These include Anhui, Beijing, Fujian, Guangdong, Hainan, Heilongjiang, Hubei, Hunan, Jilin, Shandong, Shanghai, Shanxi, Shaanxi, Sichuan, Tianjin.

35. We conducted some interviews face-to-face and some by telephone. We started the conversation with questions about media consumption, followed by questions about seeking information about politics and posting, sharing, or commenting about politics on the social media platforms. In order to capture the meaning of politics in China's context we prompted users with three expressions referring to politics: news and social hot topics (Shishi yu Shehui Redian 时事 与社会热点), political news and social hot topics (Shizheng $y u$ Shehuiredian 时政与社会热点), and major national affairs (Guojia Dashi 国家大事).

36. Interview with 88206, February 2016; Interview with 80238, December 2015.

37. Interview with 81738 , January 2016 .

38. Each episode of Weirdo Talk features a debate competition on a chosen topic between two groups of debaters; it is renowned for the wild and extreme arguments the players can make on the show.

39. Interview with 81738 , January 2016.

40. Interview with 81738 , January 2016

41. Interview with 81738, January 2016.

42. Interview with 34884, February 2015.

43. Interview with 82206, December 2015; Interview with 80238, December 2015; Interview with 89142, January 2016.

44. Interview with an associate professor of social psychology (71963) and an assistant professor of political science (70696), March 2015.

45. Interview with a Baidu Tieba senior product manager (72906), April 2015.

46. Interview with 80643, November 2015.

47. Interview with 80643, November 2015 .

48. Interview with 81402, January 2016 .

49. Interviews with three academics studying social media, October 2014.

50. Interview with a Weibo product manager (75591), April 2015.

51. Interview with a former member of a provincial news center (70235), April 2015.

52. Interview with a former member of a provincial news center (70235), April 2015.

53. Interview with a Baidu Tieba senior product manager (72906), April 2015.

54. Interview with an associate professor in social psychology (71963), March 2015.

\section{REFERENCES}

Allport, Floyd H.1937. "Toward a Science of Public Opinion." Public Opinion Quarterly 1, no. 1: 7-23. 
Bakshy, Eytan, Jake M. Hofman, Winter A. Mason, and Duncan Watts. 2011. "Everyone's an Influencer: Quantifying Influence on Twitter." Proceedings of the Fourth ACM International Conference on Web Search and Data Mining (Kowloon Hong Kong February 9-12). The Association for Computing Machinery.

Bandurski, David. 2008. "China's Guerrilla War for the Web." Far Eastern Economic Review, July 7, 41-44.

Bennett, Stephen E., Richard S. Flickinger, and Staci L. Rhine. 2000. "Political Talk Over Here, Over There, Over Time." British Journal of Political Science 30, no. 1: 99-119.

Best, Samuel J., and Brian S. Krueger. 2006. "Online Interactions and Social Capital: Distinguishing between New and Existing Ties." Social Science Computer Review 24: 395-410.

Blumer, Herbert. 1948. "Public Opinion and Public Opinion Polling." American Sociological Review 13, no. 5: 542-49.

Boas, Taylor. 2006. "Weaving the Authoritarian Web: The Control of Internet Use in Nondemocratic Regimes." In How Revolutionary Was the Digital Revolution?: National Responses, Market Transitions, and LGobal Technology, edited by John Zysman and Abraham Newman, 373-90. Palo Alto: Stanford University Press.

Boase, Jeffrey, John B. Horrigan, Barry Wellman, and Lee Rainie. 2006. "The Strength of Internet Ties." Pew Research Center, January 25. http:// www.pewinternet.org/2006/01/25/the-strength-of-internet-ties/.

Brady, Anne-Marie. 2008. Marketing Dictatorship: Propaganda and Thought Work in Contemporary China. Lanham, MD: Rowman and Littlefield.

Cebrian, Manuel, Iyad Rahwan, and Alex "Sandy" Pentland. 2016. "Beyond Viral." Communications of the ACM 59, no. 4: 36-39. doi: 10.1145/2818992.

Chase, Michael, and James Mulvenon. 2002. You've Got Dissent! Chinese Dissident Use of the Internet and Beijing's Counter-Strategies. Santa Monica, CA: RAND

Coleman, James. 1990. Foundations of Social Theory. Cambridge, MA: Harvard University Press.

Converse, Philip. 1987. "Changing Conceptions of Public Opinion in the Political Process" (Part 2). Public Opinion Quarterly 51:12-24.

Correa, Teresa, Amber Willard Hinsley, and Homero Gil de Zúñiga. 2010. "Who Interacts on the Web?: The Intersection of Users' Personality and Social Media Use." Computaters in Human Behavior 26, no. 2: 247-53. doi: 10.1016/j.chb.2009.09.003.

Davison. W. Phillips. 1958. "The Public Opinion Process." The Public Opinion Quarterly 22, no. 2: 91-106.

della Porta, Donatella. 1988. "Recruitment Processes in Clandestine Political Organizations: Italian Left-Wing Terrorism." In From Structure to Action, edited by Bert Klandermans, Hanspeter Kriesi, and Sidney Tarrow. Greenwich: JAI Press.

Delli Carpini, Michael X., Fay Lomax Cook, and Lawrence R. Jacobs. 2004. "Public Deliberation, Discursive Participation, and Citizen Engagement: A Review of the Empirical Literature." Annual Review of Political Science 7: 315-44.

Esarey, Ashley, and Qiang Xiao. 2008. "Political Discourse in the Chinese Blogosphere: Below the Radar." Asian Survey 48, no. 5: 752-72.

Flache, Andreas, and Michael W. Macy. 1996. "The Weakness of Strong Ties: Collective Action Failure in a Highly Cohesive Group." Journal of Mathematical Sociology 21, no. 1-2:3-28.

Freelon, Deen G., Travis Kriplean, Jonathan Morgan, W. Lance Bennett, and Alan Borning. 2012. "Facilitating Diverse Political Engagement with the Living Voters Guide." Journal of Information Technology and Politics 9, no. 3: 279-97. doi: 10.1080/19331681.2012.665755.

Gibson, Rachel, and Marta Cantijoch. 2013. "Conceptualizing and Measuring Participation in the Age of the Internet: Is Online Political Engagement Really Different to Offline?" The Journal of Politics 75, no. 3: 701-16. doi: doi:10.1017/S0022381613000431.

Gladwell, Malcolm. 2002. The Tipping Point: How Little Things Can Make a Big Difference. Boston: Little Brown.
Goel, Sharad, Ashton Anderson, Jake Hofman, and Duncan J. Watts. 2016. "The Structural Virality of Online Diffusion." Management Science 62, no. 1: 180-96. doi: doi:10.1287/mnsc.2015.2158.

Granovetter, Mark. 1973. "The Strength of Weak Ties.” American Journal of Sociology 78: 1360-80.

Hampton, Keith N. 2003. "Grieving for a Lost Network: Collective Action in a Wired Suburb." Information Society 19: 417-28.

Han, Rongbin. 2015. "Combating Corruption Online: Citizen Participation and State Responses in China." Paper presented at the Annual Meeting of the American Political Science Association, San Francisco, September 5.

Hartford, Kathleen. 2005. "Dear Mayor: Online Communications with Local Governments in Hangzhou and Nanjing." China Information 19, no. 2: 217-60.

Haythornthwaite, Caroline. 2002. "Strong, Weak, and Latent Ties and the Impact of New Media." Information Society 18, 385-401.

Jiang, Min, and Heng Xu. 2009. "Exploring Online Structures and Chinese Government Portals: Citizen Political Participation and Government Legitimation." Social Science Computer Review 27, no. 2: 174-95.

Kavanaugh, Andrea, Debbie Denise Reese, John M. Carroll, and Mary Beth Rosson. 2005. "Weak Ties in Networked Communities." Information Society 21: 119-31.

Klandermans, Bert, and Jacquelien van Stekelenburg. 2013. "Social Movements and the Dynamics of Collective Action." In Oxford Handbook of Political Psychology, 2d ed., edited by Leonie Huddy, David O. Sears and Jack S. Levy. Oxford: Oxford University Press.

Lasswell, Harold D. 1930. Psychopathology and Politics. Chicago, IL: The University of Chicago Press.

Laurel, Brenda. 1986. "Interface as Mimesis." In User-Centered System Design: New Perspectives on Human-Computer Interaction, edited by Donald A. Norman and Stephen W. Draper, 67-86. Hillsdale, NJ: Lawrence Erlbaum.

1997. "Interface Agents: Metaphors with Character." Human Values and the Design of Computer Technology, edited by Batya Friedman, 207-19. Stanford, CA: CSLI Publications.

Lee, Chin-chuan. 2000. "Chinese Communication: Prisms, Trajectories, and Modes of Understanding." In Power, Money, and Media: Communication Patterns and Bureaucratic Control in Cultural China, edited by Chin-chuan Lee, 3-44. Evanston, IL: Northwestern University Press.

Lodge, Martin, and Kai Wegrich. 2015. "Crowdsourcing and Regulatory Reviews: A New Way of Challenging Red Tape in British Government?' Regulation and Governance 9, no. 1: 30-46. doi: 10.1111/rego.12048.

Lotan, Gilad. 2011. "Understanding Audiences through Information Flows." http://giladlotan.com/2011/06/understanding-audiences-through-informa tion-flows/, accessed on August 15, 2016.

2012. "A Tale of Three Rumors." http:/giladlotan.com/2012/03/atale-of-three-rumors/, accessed on August 15, 2016.

MacKinnon, Rebecca. 2009. "China's Censorship 2.0: How Companies Censor Bloggers." First Monday 14, no. 2

2012. Consent of the Networked: The Worldwide Struggle for Internet Freedom. New York: Basic Books.

McMillan, Sally J. 2002. "A Four-Part Model of Cyber-Interactivity: Some Cyber-Places Are More Interactive than Others." New Media and Society 4, no. 2: 271-91. doi: 10.1177/146144480200400208.

Morozov, Evgeny. 2011. The Net Delusion: How Not to Liberate the World. London: Penguin Books.

Pan, Zhongdang, Lijiang Shen, Hye-Jin Paek, and Ye Sun. 2006. "Mobilizing Political Talk in a Presidential Campaign: An Examination of Campaign Effects in a Deliberative Framework." Communication Research 33, no. 5: 315-45. doi: 10.1177/0093650206291478.

Qiu, Jack Linchuan. 2000. "Virtual Censorship in China: Keeping the Gate Between the Cyberspaces." International Journal of Communications Laws and Policy 4: 1-25. 
Reilly, James. 2012. Strong State, Smart State: The Rise of Public Opinion in China's Japan Policy. New York: Columbia University Press.

Stockmann, Daniela. 2013. Media Commercialization and Authoritarian Rule in China, Communication, Society and Politics Series. New York, NY: Cambridge University Press.

Vegh, Sandor. 2003. "Classifying Forms of Online Activism: The Case of Cyberprotests against the World Bank." In Cyberactivism: Online Activism in Theory and Practice, edited by Martha McCaughey and Michael D. Ayers, 71-96. New York: Routledge.

Wellman, Barry. 2001. "Computer Networks as Social Networks.” Science 293: 2031-34.
Xiao, Qiang. 2011. "The Rise of Online Public Opinion and Its Political Impact." In Changing Media, Changing China, edited by Susan Shirk, 202-24, Oxford: Oxford University Press.

Yang, Guobin. 2009. The Power of the Internet in China: Citizen Activism Online. New York: Columbia University Press.

Zhang, Shanruo Ning. 2015. Confucianism in Contemporary Chinese Politics: An Actionable Account of Authoritarian Political Culture. Lanham, MD: Rowman and Littlefield.

Zhao, Yuezhi. 1998. Media, Market, and Democracy in China: Between the Party Line and the Bottom Line. Urbana: University of Illinois Press. 